\title{
KISKUNFÉLEGYHÁZA CITY HOSPITAL AND CLINIC, BATH AND REHABILITATION CENTER DEVELOPMENT AND SOME CONTEXT OF PATIENT SATISFACTION AND LOGISTICS Róbert Fekete $^{1}-$ József Gál $^{2}$
}

\author{
${ }^{1}$ Kiskunfélegyháza City Hospital and Clinic, Bath and Rehabilitation Center, \\ H-6100 Kiskunfélegyháza, Fadrusz J. u. 4, Hungary \\ e-mail: dfekete.robert@gmail.com \\ ${ }^{2}$ University of Szeged, Faculty of Engineering, \\ H-6724 Szeged, Mars tér 7, Hungary \\ e-mail: ali@mk.u-szeged.hu galj@mk.u-szeged.hu
}

\begin{abstract}
The study of Kiskunfélegyháza hospital rehabilitation department of the launch and operation are summarized in the light of the results data. Started in May 2005, public investment is achieved, containing functional reconstruction of partial hospitalization as a result of enlargement, was delivered in September 2006, was built to exploit the thermal rehabilitation unit, which includes a 40-bed department on the first floor, the ground floor clinic rooms, the spa offers therapeutic and physiotherapy service rooms and swimming pools, the basement of mechanical rooms. A further problem in question - the subject-oriented guide to healing, health, illness, and a definition of rehabilitation took place - according to the literature. It will be determined in the prevention, injury, disability and concepts of disability in the light of the logistics. Write the process that accompanies the service, taking into account the economic aspects of the market.

Have been processed under the rehabilitated patient population, patient registration data by age between 2007 and 2012. Considering the cases of the total care days are the number of transferees from other classes, social and home placement per capita average care days in the bed occupancy and the number of death cases were surveyed on written questionnaires.

Rehabilitation hospital care is most effective with measurable - which can be seen in the analysis - that of the average length of more than 18 days, the bed occupancy of $100 \%$ and a mortality rate of $2 \%$. However, the situation logistical aspects of the process can be improved further by examining the quantitative and qualitative indicators of well. The topic niche processing, rehabilitation domestic situation analysis has been very little. The results are set out proposals to increase the efficiency of operation.
\end{abstract}

Keywords: rehabilitation, logistics, musculoskeletal rehabilitation, therapy, post operation treatment

\section{INTRODUCTION}

Kiskunfélegyháza is lucky thermal characteristic features, which provides public bathing facilities for the general public for decades. People - in folk medicine - realized the benefits of, and then this option is left unused for a long time. During the health care systems, is an excellent opportunity offered itself as a mineral water based uptake rehabilitation, intensive development in the city. Since the first of January 2011 has started in Kiskunfélegyháza hospital musculoskeletal rehabilitation clinics funded by the National Health Insurance (OEP) 9 hours a week, which is controlled by two specialist medical doctor. 
Direct territorial coverage obligation of consultation covers 52,000 inhabitants in Kiskunfélegyháza and its surroundings, as well as indirectly and partially Bács-Kiskun and Csongrád counties' population. How to get in movement or activities disabled patients through general medical doctor - to a special rehabilitation center from their home? How many hurdles to overcome not only because of the disability, but the access generally as well? After following the general medical care, or previous clinical care, follow-up examination clinic reference to quotations made by the dispatching computer program to book appointment (exact month, day, hour graduations) for 15-minute intervals to share by your personal contact or telephone appointment negotiation call.

\section{MATERIALS AND METHODS}

The rehabilitation activities and related logistics processed and a short summary of the literature. Questionnaire survey among patients treated in the hospital department. Summary and some forward thinking wording.

\section{SUPPLY OPTIONS, SWIMMING COMPLEX MEDICAL TREATMENT}

Offered facilities and by Kiskunfélegyháza City Hospital and Clinic, Bath and Rehabilitation Center

A) medicinal water pool

Mud pack, carbonic acid bath, water jet massage / underwater jet massage / massage, weight bath, underwater gymnastics group.

B) physiotherapy treatments

Iontoforésis (using various gels rheumatism), ultrasound treatment, landing, four compartments and other galvanic treatments, TENS therapy to strengthen the purpose of pain, nerve stimulation, diadynamic current, Bemer and magnet therapy.

C) physiotherapy: Physiotherapy is the most special tournaments and the Mc. Kenzeigymnastics, the suspension grid) and joint use of moving machinery. (A. S. LEON ET AL. 2005; M. F. PIEPOLI ET AL. 2010; E.G. 2012; S. GEROLD ET AL. 2007)

The assigned team members are, physical therapists, physiotherapists, masseurs, lifeguards, specialized doctors, assistants, patients, and last but not least, providing transportation and carrying out staff, patient transport family members by car or public transport, train, bus, and not insignificantly electric wheelchair, using a bicycle take the smooth operation of the unit. Everything has to count the cost of which lies directly or indirectly, but the patient. (Szegedi Z. - Prezenszki J. 2010; Szabó Gy., Renner A. 2004)

The specialist doctor ordered therapy according to the disease, like number and the composition of the treatment and patients get treatment sheet. It is a spa treatments medical prescription. Then, the patient controls the form and the combination of vehicles visiting the dispatcher service for the purpose of accounting for compensation cost and schedule of treatments.

Part $o$ the treatments paid by TB (medical insurance) as a fixed portion and the rest is paid by the patient. In the case of public health beneficiaries, the service is free of charge. Timing of schedule starts, chosen the earliest possible time, leaving no empty space in view of the high degree of efficiency and demand. Generally, waiting for treatment the average of days is between 10 days and two weeks. Having been ready administration treatment logistics starts, using above mentioned tools, and knowledge of the exact dates. Control compulsory for the patient, in order that check efficiency, effectiveness in order to assess the importance of logistics process is repeated test within 3 weeks after completion of treatment. 
The above figure shows that over the past six years - during the development of the department's image - an average of nearly 1,000 patients treated per year. Ensuring continuity of patient care mentioned earlier could only be a result of well-organized logistics process. Carefully planned work in liaison with the surgeon and acute departments who want their patients' rehabilitation in Kiskunfélegyháza. Patients that they are the class after a telephone consultation, and may place patients rehabilitated made redundant at the scheduled time of the next patient bed occupancy, in addition to the overall economy is. In addition, home of the patients in the pre-notification ticket is sought, up to one week prior to the recording by phone call. Perform some tests before the shooting - which are essential for successful rehabilitation - outpatient needs to be, that the cost of the hospital's budget is not burdened (x-rays, lab etc.) too. It is important that the available recording time of the patients known drugs, the medication should be smooth. This requires a range of medicines to ensure the accuracy of the hospital logistic processes by which the suppliers created as a result. In the last two years has increased the territorial obligation, since 1st October 2010 from Kecskemét County Hospital to Kiskunfélegyháza 32 musculoskeletal rehabilitation beds have been moved, so increased the capacity of the musculoskeletal rehabilitation department. In the past 20 musculoskeletal beds capacity has increased up to 52 beds and the existing 20 bed cardiovascular unit that has 72 beds, which are the total number of beds in the rehabilitation department. With the number of patients around 1/3-dal increased compared to 2010. (FIGURE 1) However, neither the human nor the technical resources are not increased, thus significantly hard-working staff, which requires using the capacity of the human resources available.

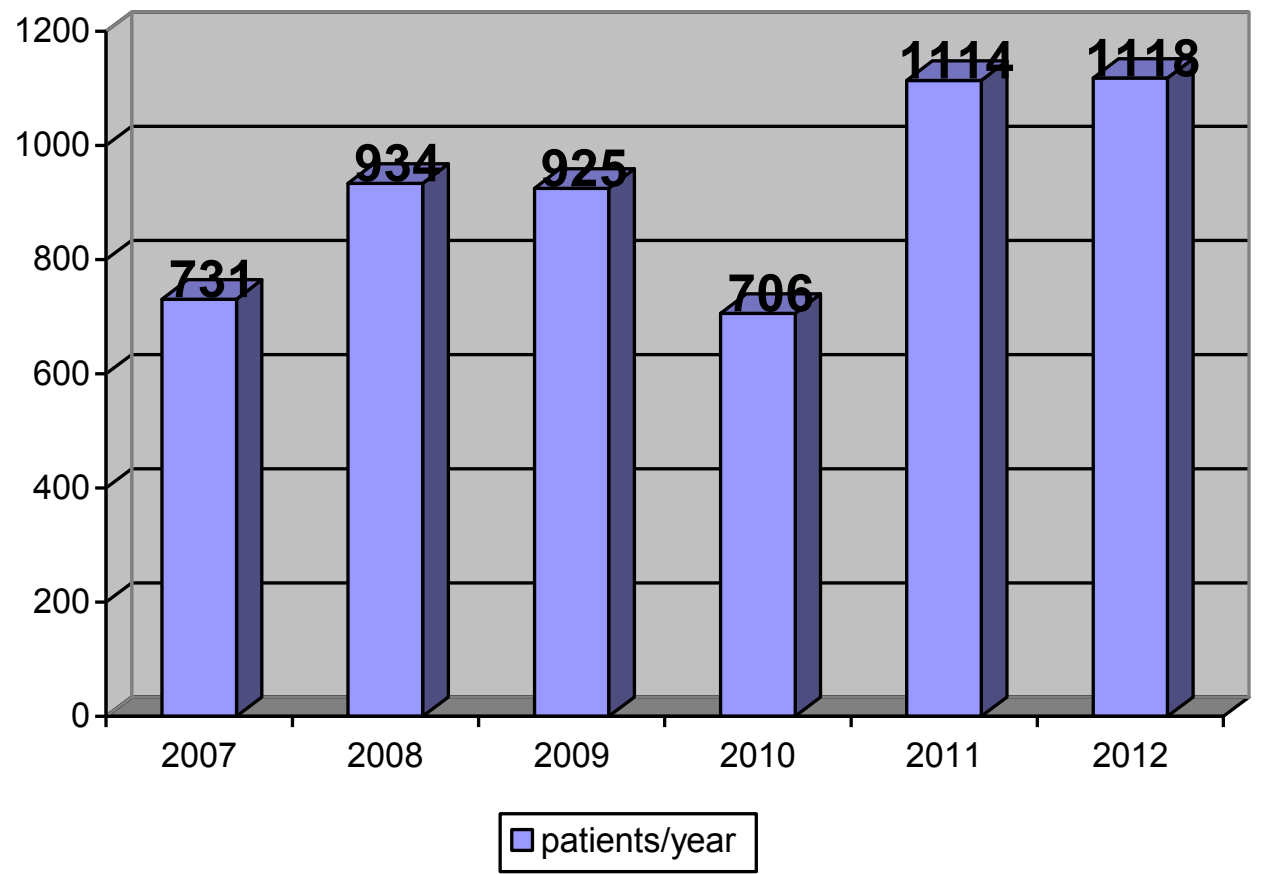

Figure 1 Patient turnover 2007-2012 patient/year

Source: Authors' own data

This is the point where it is very thought-provoking insights to strategically what further action is possible for the department to meet growing patient care needs. Given that the infrastructure does not allow the inclusion of more beds, overcrowding would become inevitable, as is the case in many other domestic institutions is already visible. The increase in 
staff numbers, mainly due to known medical deficiency, on the other hand the non- medical staff wage bill increase further undermine the position of the class.

\section{A REPRESENTATIVE SURVEY OF PATIENTS REHABILITATION OF A WORKING OF CLASS (SURVEY)}

2013 survey done by the department treated patients in order to measure the work quality of the medical staff. A random selection of patients responding occurred, highlighting patients to different age, gender, educational level and social level of the database. 100 questionnaires were issued, of which 61 were processed was because the only answer to all your questions on tax questionnaires could be evaluated. The sampling period was three weeks because he planned to spend three weeks in most of the patients in the ward.

The survey aims to provide a cross-sectional picture of the operation of the department of users of opinion that the standard of the personnel work of the well-being of patients, refer to the state of healing. Received particular attention was in the compilation of the questionnaire aspects simple to use, comprehensible station, clarity, ease of answering and interpretability. The questionnaires were in the days before discharge rates in patients after completion of the final report is handed over we got back.

Specific questions were as follows:

- Why did you choose your class for the purpose of rehabilitation management?

- The x-th time away in our department?

- Satisfaction of operating personnel (doctor, nurse, physiotherapist, physiotherapists, bath with crew), and the efficacy of treatments?

- If you have been lying in our hospital, the present management and the effectiveness of previous treatment how do you judge?

- Does the department received information in a clear explanation of the objectives of the state of the disease, and the results of medical treatment studies?

- Do you want the option to continue rehabilitation at our institution to continue?

- Do you recommend to our class to others?

The answer is choice (yes-no) and 1 to 10 points for evaluation occurred.

\section{RESULTS AND DISCUSSION}

The 61 interviewed patients, 17 men, 44 women were, this ratio is broadly representative of the patient's circulation is observed, the composition of sex. The mean age of patients 65.7 years, the youngest 31 , the oldest was 83 years old. Half of the patients were previously informed from the rehabilitation department (31 patients) or other institution offered or heard in the general population, or read about it in the media. 1/3- respondents ( 22 patients), other inpatient institute sent after acute events, as cardiac surgery, heart attack, hip nailing, prosthesis implantation them. Sample one-third of the number of cases examined accounts. (The questionnaires were processed with the help of Excel.) Therefore it may be legitimate for sub-acute rehabilitation name. 36 patients it was in order to institute rehabilitation to one care (hospital active clinic department, orthopedics, rheumatology, traumatology, surgery, cardiology, neurology) initiated the referral were a surprisingly large proportion of those (25 patients), whose family doctor suggested to the clinics in the rehabilitation care needs. A number of returning patients are usually among the beneficiaries, on average, three times so far lay there, the answers were between 1 and 10 times. Data presented in the previous section of the paper clearly show that, since the musculoskeletal rehabilitation participants exceeds $50 \%$ of cases each year, and cardiovascular patients in $30 \%$. 
Positive responses were received almost maximum satisfaction issues. The management staff, they were all satisfied, the potential 10-point average of 9.8 doctors and 9.5 nurses, physiotherapists 9.6, 9.3 physiotherapists, the spa personnel received 9.3 points. The effectiveness of the treatments were mostly pleased with the 9.4 gym, physiotherapy 8.9 , the spa treatment was 9.3 points. During the rehabilitation period, $88 \%$ (54 patients) felt that they had improved to about 12\% (7 patients) left unchanged. To the question that you have received this information due to illness, the state of the tests and their results, the medical treatment, all patients answered yes. Almost all respondents happy to return to and would recommend it to other patients Kiskunfélegyháza rehabilitation clinic department.

\section{SUMMARY}

Should be aware that the patient's recovery will not be completed for a successful surgery. The patient should be encouraged to her old life, back to work, which requires the help of experts organized within the framework of institutional and outpatient care.

10 years ago there was no rehabilitation unit in the hospital, initially tried to establish the conditions for a successful recovery, within their own wards.

In May of 2005 started, addressed public investment realized, partial hospitalization reconstruction containing functional expansion as a result, in September 2006, was handed over to the thermal-recovery built rehabilitation unit, which includes the 40-bed department participated in the floors, the ground floor clinic rooms, the spa offers therapeutic and physiotherapy service rooms and the swimming pools, the basement of the horseradish rooms and mechanical rooms.

100 questionnaires were issued, of which 61 has been working on, which represented the class works. The respondents were slightly more than a quarter of men, the average age of nearly 66 years, which shows that more were treated in the older age group. Half were treated as described in our institution, which is not considered a bad number ratio. What is also good that, half of the patients directed to other institutes. As to how many times you have been lying in our department, the average was close to 3.5, the majority (34\%) 1-2 times taken advantage of our services. Maximum level of positive responses is to the operating personnel and the efficacy of treatments given. The efficacy of physiotherapy was held just under $90 \%$ of. In connection with their condition has improved to $90 \%$ of the response was yes . Over $90 \%$ of new management took effective as it was earlier. $100 \%$ of respondents would like to further continue their treatment at our institution and recommend to others.

The investigation confirmed expectations, because their experience has shown that, over the years, the patients took a liking to the institution, regardless of age, gender, social status as to, satisfied with their services. The rate of re-admissions are high, many people are patiently waiting for the subscription period already in excess of half a year now. Currently, the waiting list of more than 800 patients have pre-registered, which is a very large number. The urgent recruitment needs, and suffered an acute event, other regional treatment sites insist to Kiskunfélegyháza hospital. Rehabilitation hospital care is most effective in the analysis which can be measured by looking at well-defined - that the average number of nursing for more than 18 days, the bed occupancy of $100 \%$ and a mortality rate of $2 \%$. Errors, that rehabilitation is very little analysis on the domestic situation, which could increase the efficiency of the operation. 


\section{REFERENCES}

A. S. Leon et al. (2005): Cardiac Rehabilitation and Secondary Prevention of Coronary Heart Disease An American Heart Association Scientific Statement From the Council on Clinical Cardiology (Subcommittee on Exercise, Cardiac Rehabilitation, and Prevention) and the Council on Nutrition, Physical Activity, and Metabolism (Subcommittee on Physical Activity), in Collaboration With the American Association of Cardiovascular and Pulmonary Rehabilitation. Circulation. 2005; 111: 369-376.

E.G. (2012) European Guidelines on cardiovascular disease prevention in clinical practice: The Fifth Joint Task Force of the European Society of Cardiology and Other Societies on Cardiovascular Disease Prevention in Clinical Practice (constituted by representatives of nine societies and by invited experts). Developed with the special contribution of the European Association for Cardiovascular Prevention \& Rehabilitation . Eur Heart J, 2012 33: $1635-1701$

M. F. Piepoli et al. (2010): Secondary prevention through cardiac rehabilitation: from knowledge to implementation. A position paper from the Cardiac Rehabilitation Section of the European. Association of Cardiovascular Prevention and Rehabilitation. E. J. Cardiovasc. Prev. and Rehab.

S. Gerold et al. (2007): The International Classification of Functioning, Disability and Health: A unifying model for the conceptual description of the rehabilitation strategy. J. Rehab. Med. 2007, 39: 279.

Szegedi Z. - Prezenszki J. (2010): Logisztika-Menedzsment (Logistics-Management). Kossuth. Budapest

Szabó Gy., Renner A. (2004): A rehabilitáció gyakorlata (Rehabilitation is Practice). Medicina. Budapest 